\title{
Temas transversais ou conteúdos disciplinares? Cultura, cidadania e diferença
}

Transversal themes or disciplinary contents? Culture, citizenship and difference

\section{Thèmes transversaux ou contenus pédagogiques? Culture, citoyenneté et différence}

\author{
¿Temas transversales o contenidos disciplinares? Cultura, ciudadanía y \\ diferencia
}

\author{
Maurinice Evaristo Wenceslau ${ }^{1}$ \\ Fabiany de Cássia Tavares Silva ${ }^{1}$
}

Recebido em 06/04/2017; revisado e aprovado em 02/05/2017; aceito em 17/05/2017

DOI: http://dx.doi.org/10.20435/inter.v18i4.1562

\begin{abstract}
Resumo: O texto apresenta resultados de pesquisa que analisou a representação das noções de cultura, cidadania e diferença como temas transversais constantes de documentos curriculares publicados no período de 2000 a 2008 por uma rede municipal de ensino, particularmente destinados ao ensino fundamental. O desenho metodológico da análise orientou-se pelas ferramentas do estudo comparado de caráter bibliográfico-documental.
\end{abstract}

Palavras-chave: currículo, cultura, cidadania, diferença, ensino fundamental.

\begin{abstract}
The text we presents the results of research that analyzed the representation of the notions of culture, citizenship and difference as transversal themes found in curriculum documents published from 2000 to 2008 by a municipal school system, particularly intended for elementary school. The analysis included the methodological tools of the comparative study of bibliography and documents.
\end{abstract}

Key words: curriculum, culture, citizenship, difference, elementary school.

Résumé: Dans ce mémoire nous présentons les résultats d'une recherche portant sur la représentation transversale des notions de culture, de citoyenneté et de différence dans des documents pédagogiques publiés entre 2000 et 2008 par les écoles d'une commune à destination des enseignants du primaire. La méthodologie utilisée a été l'étude comparative de nature bibliographique-documentaire.

Mots-clés: cursus, culture, citoyennete, difference, école primaire.

Resumen: En este trabajo hemos presentado los resultados ha analizado la representación de las nociones de la cultura, ciudadanía y diferencia, como temas tranversales presentes en documentos curriculares publicados en el periodo entre 2000 y 2008, por una red municipal de enseño, particularmente para la escuela primaria. El dibujo metodológico dicho análisis se basó en herramientas metodológicas del estudio comparado de naturaleza bibliográfica y documental.

Palabras-clave: curriculum, cultura, ciudadanía, diferencia, escuela primaria.

\section{NOTAS INTRODUTÓRIAS}

Neste texto, expomos resultados de pesquisa que, entre outros objetivos, buscou analisar como documentos curriculares publicados no período de 2000 a 2008 por uma rede municipal de ensino, particularmente destinados ao ensino fundamental, representavam as noções de cultura, cidadania e diferença. No exercício, ancoramo-nos na hipótese de que essas noções não eram operadas como temas transversais, mas como conteúdos de disciplinas acadêmicas específicas, em uma espécie de 'ensino sobre', ao invés de favorecer a construção de conscientização crítica.

Esses documentos foram eleitos por dois motivos. Primeiramente, por difundirem a orientação da educação como um direito de todos, apoiados nos valores da liberdade e da justiça social, fundados nos informes das políticas educacionais de finais dos anos 1990. Em segundo

\footnotetext{
${ }^{1}$ Universidade Federal de Mato Grosso do Sul, Campo Grande, Mato Grosso do Sul, Brasil.
} 
lugar, pela necessidade de desmistificação de que essas noções seriam suficientes para operar a orientação.

Pacheco (2007, p. 01) argumenta que o currículo deve estar comprometido com uma educação para a cidadania democrática:

Como espaço aberto de construção do percurso das pessoas, a escola pública é um mecanismo complexo que exige não só o questionamento do conhecimento, que a coloca na base dos conflitos, mas também a interrogação sobre os modos de tornar a cidadania num projeto educativo que não esteja continuamente a ser adiado.

A abordagem desejável, sob a perspectiva deste estudo, está centrada na procura pelos mecanismos de identificação da construção de currículos a serviço de mudanças sociais. Tal visão encaminha para a gestão das diferenças como princípio de práticas curriculares, cujo propósito é contribuir para a emancipação dos indivíduos, ou melhor, uma educação 'além do Capital' (Cf. MÉSZÁROS² 2005), isto é, a construção de práticas pedagógicas geradoras, não só de reprodução sociocultural, mas também de emancipação e transformação da realidade.

Orientamos o desenho metodológico pelas ferramentas do estudo comparado de caráter bibliográfico-documental, configurando as noções de cultura, cidadania e diferença como áreas de comparação. Essas noções foram submetidas ao exercício de alargamento da transversalidade, isto é, não apenas como meio para superar a fragmentação do conhecimento escolar, mas na busca de suas traduções no contexto do discurso em prol da 'escola justa', constante dos documentos curriculares.

\section{CULTURA, CIDADANIA E DIFERENÇA: A CIÊNCIA JURÍDICA COMO “LUGAR” DE PRODUÇÃO CONCEITUAL}

A evolução cultural de cada sociedade deveria ser analisada na discutição sobre cidadania e diferença, uma vez que o homem passou a viver em grupo. Diante disso, nada seria puramente natural. Todos os comportamentos seriam estabelecidos pela cultura, o que remeteria à compreensão da divergência de respostas dadas a essas necessidades, em decorrência das diferenças de agrupamento social.

A cultura possibilitaria a unidade do homem, respeitando suas diversidades quanto ao modo de vida e de crença, a aculturação. "A aculturação aparece não como um fenômeno ocasional, de feitos devastadores, mas como uma das modalidades habituais da evolução cultural de cada sociedade" (CUCHE, 1999, p. 14).

O processo cultural se habituaria às normas morais, de acordo com evolução do grupo, fazendo surgir novas prioridades, na contingência de mudar tais normas. A proteção dos valores culturais não poderia ser fixada globalmente, submetendo-se ao processo inovador da mudança,

\footnotetext{
${ }^{2}$ Para o autor, "[...] a educação institucionalizada, especialmente nos últimos 150 anos, serviu - no seu todo - ao propósito de não só fornecer os conhecimentos e o pessoal necessário à máquina produtiva em expansão do sistema do capital, como também gerar e transmitir um quadro de valores que legitima os interesses dominantes [...]" (MÉSZÁROS, 2005, p. 35). Sob esta perspectiva, propõe uma ruptura educacional ampla, que compreenda não só os espaços escolares, mas uma educação "para toda a vida", comprometida com ideais transformadores, para promover "transformações políticas, econômicas, culturais e sociais necessárias" (idem, p. 10). Para isso, segundo ele, é preciso "desafiar as formas atualmente dominantes de internalização, fortemente consolidadas a favor do capital pelo próprio sistema educacional formal” (idem, p. 55) e romper com a lógica do capital e com a reprodução das formas de dominação consubstanciadas na sociedade capitalista.
} 
que seria o segredo de sua sobrevivência. Diante disso, a cultura possibilitaria a unidade do homem, respeitando as suas diversidades quanto ao modo de vida e de crença, a aculturação.

Quando interpretamos a cultura, não levamos em conta apenas o seu sentido antropológico, mas também o valorativo, uma vez que, mesmo assegurado pelo Estado o pleno exercício dos direitos culturais, em certas situações o interessado deve reivindicar esse exercício. Seria responsabilidade do Estado concretizar a realização do direito em questão, com fundamento no artigo $215^{3}$ da CRFB.

Diante disso, a não operação de restrição ao conceito de cultura, isto é, vê-la apenas como a criação artística ou intelectual, vai ao encontro do que preconiza a Carta Magna vigente. Contudo destacamos, por outro lado, que o fato de não ter oferecido conceito muito extenso acabou deixando a expressão sem parâmetros. Na visão constitucional, passou a ser "[...] um sistema de hábitos compartilhados por membros de uma sociedade, seja ela uma tribo ou uma nação civilizada. Criar cultura consiste em transformar realidades naturais ou sociais, mediante a impregnação de valores" (SILVA, 2001, p. 29).

A identidade prevista no texto constitucional e a ação e a memória dos diversos grupos formadores da sociedade brasileira ampararam o conceito da cultura, ao mesmo tempo em que incluíram todos os movimentos de reivindicação dos diferentes grupos, ajudando na ampliação da

[...] compreensão da cultura e da política em países que buscam instituir uma democracia participante. Isso também pode desqualificar as análises que dividem os movimentos sociais em duas correntes: as que buscam a afirmação cultural e aqueles que querem acesso mais amplo aos recursos. Ao perceber a importância de reconhecer e redistribuir o capital cultural [...]. (WARREN, 2000, p. 287).

A cultura Constitucional, que não poderia ser dissociada de grupos e classes sociais, constituiu-se em um campo de conflito dado pela manutenção ou superação das divisões sociais. O Poder Público deveria exercer o papel de favorecer a livre procura das manifestações culturais, criando o acesso popular à cultura e provendo meios para que a expansão cultural se fundamentasse nos critérios de igualdade.

A ação cultural do Estado eficaz se conduziria pela busca da realização da igualização dos socialmente desiguais, ou seja, democratizando a cultura, para que todos, igualmente, tirassem benefícios dela. Nesse processo, a cidadania consistiu no gozo pleno de direitos na sociedade política. A concepção deu forma à noção moderna de mundo, fundada nos direitos individuais, racionais e em noções como civilidade e progressividade.

A cidadania, além do direito ao voto e à liberdade de participação político-partidária, figurava como o direito conferido àqueles que participavam das decisões políticas de um determinado Estado, buscando concretizar os direitos fundamentais, individuais e coletivos, como o direito à educação, à igualdade formal e/ou material, e à não discriminação, entre outros.

Os direitos fundamentais objetivavam assegurar a proteção à dignidade humana, assumindo função fundamental, compreendidos como pressupostos à vida digna e à liberdade do cidadão, como fonte de poder legítimo (MORGAN, 2006, p. 2). Assim, a garantia dos direitos fundamentais exigiu um Estado Democrático e a ampliação do compromisso com os Espaços Sociais, materiais e subjetivos, com a vida pública e com a liberdade material e política do cidadão. A ampliação foi

\footnotetext{
3 "O Estado garantirá a todos o pleno exercício dos direitos culturais e acesso às fontes da cultura nacional, e apoiará e incentivará a valorização e a difusão das manifestações culturais" (BRASIL, 1988).
} 
dada pela necessidade de dinamização do poder institucional com os interesses da sociedade civil.

Sublinhamos que a cidadania era intrínseca ao movimento democrático, que se legitimava com a criação, instituição e ampliação de direitos e deveres, suficientes à abertura dos Espaços Sociais nas sociedades democráticas.

No Brasil, o destaque da proteção dos direitos fundamentais e da cidadania foi concomitante ao processo de redemocratização institucional. Com o fim dos governos ditatoriais, ocorreu um processo significativo de participação popular, culminando na reunião do poder constituinte originário e na consequente promulgação da Constituição Federal de 1988. O texto constitucional consagrou os direitos fundamentais do cidadão brasileiro: a cidadania, a vida digna, a liberdade, a igualdade e a solidariedade.

Para Guerra (2012, p. 17), a cidadania assumiu uma propositura com a contemporaneidade, de forma interdependente e indivisível. Em tal processo a cidadania, a liberdade, a justiça política, social e econômica, a igualdade de chances e de resultados e a solidariedade estavam vinculadas aos objetivos dos Direitos Humanos.

Apesar da importância da conexão entre as propostas de cidadania e de Direitos Humanos, havia necessidade de que os Estados democráticos contemporâneos fossem inoperantes na efetividade desses direitos. Atualmente, existe "um enfraquecimento da percepção da responsabilidade, da solidariedade, que inviabiliza a moralidade positivada entre cidadãos" (MORIN, 2000, p. 106). O enfraquecimento desses valores "provocou uma restrição material da cidadania e da cultura democrática com as desigualdades e marginalizações sociais, gerando uma relação meramente formal entre cidadãos, sociedade e Estado." (VIOLA, 2007, p. 129-31).

Os textos constitucionais brasileiros, principalmente o vigente, estenderam o campo de aplicação dos direitos fundamentais e da cidadania, particularmente por meio da adoção de Governo Democrático, que teria como fundamentos a igualdade e a liberdade, levando ao fortalecimento das garantias do exercício da cidadania e do livre exercício da democracia.

A liberdade, prevista no art. 5으, II da $\mathrm{CRFB}^{4}$, consistiu no direito de todos em fazer e de não fazer o que bem entendessem, exceto quando a lei determinava em contrário. A liberdade de manifestação ficava restrita, exclusivamente por lei, ao princípio da legalidade, correlacionadas por tal dispositivo legal à liberdade e à legalidade.

Essas ponderações asseguravam espaço para uma interação entre os cidadãos e a sociedade envolvente, em condições de igualdade, fundada na garantia do direito à diferença. A diferença foi compreendida a partir da ordem dos contrários, algo tido como irreversível, que não se misturava e que, por vezes, se relacionava à desigualdade, entendida a partir da ordem das contradições.

Já o conceito de cidadania foi delineado em torno de um sujeito coletivo, estritamente ligado à sociedade e ao Estado democrático, que surgia diante da percepção da necessidade de lutar por um direito negado ou de difícil acesso, que produzia a carência social, em decorrência da ineficiência do Estado no cumprimento da distribuição dos bens essenciais à vida em uma sociedade organizada.

\footnotetext{
4 “Todos são iguais perante a lei, sem distinção de qualquer natureza, garantindo-se aos brasileiros e aos estrangeiros residentes no País a inviolabilidade do direito à vida, à liberdade, à igualdade, à segurança e à propriedade, nos termos seguintes: [...] II- ninguém será obrigado a fazer ou deixar de fazer alguma coisa senão em virtude de lei; [...]", disponível em:<http://www.planalto.gov.br/ccivil_03/constituicao/constituicao.htm>. acesso em: 14 set. 2016.
} 
A igualdade de tratamento despendido pelo Estado Democrático encaminhava à construção de diferenças na esfera pública, que acabou por provocar o surgimento de desigualdades inevitáveis, o que exigiria uma organização coletiva pelo exercício de cidadania, como, por exemplo, a organização de grupos (como associações, sindicatos, ONGs etc.) que os aproximaria dos seus direitos fundamentais.

Importante mencionar que a reivindicação dos direitos do cidadão no Estado democrático somente se efetivaria se tivessem acesso à educação, em especial a educação para a cidadania, entendida para todos, em qualquer nível, igualados pelo alcance ao ensino de qualidade.

Os Estados modernos “[...] procuraram, pela educação formal obrigatória, homogeneizar culturalmente os seus cidadãos, promovendo a sua unificação linguística, religiosa e de costumes, e criando direitos exclusivos, símbolos e rituais que os identificassem como membros de uma só nação" (GUIMARÃES, 2012, p. 42).

A igualdade balizava os valores das democracias ocidentais nos planos dos direitos civis, sociais e econômicos, e não no plano dos valores culturais e sua manifestação à igualdade pelo respeito à diferença ou à diversidade. Assim, o direito à educação, ao exercício da cidadania e ao livre exercício democrático somente seria possível se fosse inserido o direito à diversidade cultural.

Atualmente, a luta se estabelece na manutenção das identidades coletivas (raciais, étnicas, sexuais, estamentais, regionais, culturais, nacionais) em busca da sua sobrevivência, uma vez que "o princípio da diferença tem concepção fortemente igualitária no sentido de que, a menos que exista uma distribuição que melhore as pessoas [...], será preferida uma distribuição igual" (RAWLS, 1981, p. 78). O direito das minorias de ser diferente passou a ser defendido por uma maioria, em que pesem aos interesses ocultos no processo.

Observamos a relação entre o cidadão, com uma postura participativa, e a administração da sociedade política, definindo a cidadania como "[...] o estatuto que rege, de um lado, o respeito e a obediência que o cidadão deve ao Estado e, de outro lado, a proteção e os serviços que o Estado deve dispensar, pelos meios possíveis, ao cidadão" (FARAH, 2001, p. 1).

No cenário sócio-político do Brasil, apesar dos avanços, a cultura democrática de vivência social era muito tímida, pois a cidadania ativa não era exercida plenamente no cotidiano (RICHTER; TERRA; CASSOL, 2007, p. 2). Essa timidez não assegurava a legitimidade e impedia a plena acessibilidade do indivíduo ao cumprimento de seus deveres e o acesso aos seus direitos fundamentais. Também pressupunha um déficit na cidadania e a necessidade de fomento democrático.

A igualdade, balizadora dos valores nas democracias ocidentais, nos planos dos direitos civis, sociais e econômicos, manifestava-se no plano dos valores culturais pelo respeito à diferença, ou diversidade. Assim, o direito à educação e ao exercício da cidadania seria possível se fosse considerado o direito à diversidade cultural.

Os objetivos do processo educacional, segundo a Carta Constitucional, deveriam relacionar-se ao sistema de ação democrática do cidadão contemporâneo, ligando-o às responsabilidades pessoal e social, como marcas da cidadania, dentro das relações institucionais e das relações sociais.

A sociedade que se desenha abre espaço para a essencial reflexão acerca do problema ético da responsabilidade pessoal e social, precisamente no terreno da ação, onde o homem se põe à prova como um eu pessoal convocado a tomar consciência de si e de seu mundo, na comunicação intersubjetiva numa comunidade, onde nossos projetos se unem a necessidades reais no esforço de suplantar as alienações que se tecem ao nosso redor. (MORGAN, 2006, p. 4). 
A educação seria vista como prática social, instrumento pelo qual seria possível "[...] não apenas transmitir o conhecimento acumulado por determinada civilização, mas inserir o indivíduo no mundo de significados de sua comunidade" (CAMPOS, 2009, p. 564). Reconheciam-se, no ato educativo, a intencionalidade, sob a qual se educava para um fim, e a politicidade, para a qual a educação contribuiu com a formação de valores (CAMPOS, 2009, p. 564).

A emancipação do sujeito político, inserido em contextos sociais de exercício de cidadania, foi um dos primeiros passos para a superação dos paradigmas de sujeição e dominação do próprio ser-social para a acepção democrática, com liberdade e igualdade. Os documentos curriculares de uma educação para a cidadania passaram a utilizar procedimentos que viabilizavam discussões sobre cultura, cidadania e diferenças. É o que veremos a seguir.

\section{CIDADANIA, DIFERENÇA E CULTURA: ÁREAS DE COMPARAÇÃO NO EXERCÍCIO DE ANÁLISE DOS DOCUMENTOS CURRICULARES}

O conjunto de documentos curriculares que acessamos, para dar forma às análises pretendidas, foram construídos e publicados na primeira década do século XXI, por uma rede municipal de ensino de uma capital de um Estado brasileiro. Estudamos esses documentos em sua forma prescrita, entendendo que a prescrição representa a linguagem veiculada por um grupo de técnicos da rede, portanto, autorizada e investida de "autoridade pedagógica".

Esse conjunto estava constituído por três documentos: Sequência Didática, publicada no ano de 2000, em atendimento ao disposto nos Parâmetros Curriculares Nacionais (1998), segundo a premissa de que o currículo seria facilitador do desenvolvimento de habilidades, com a intenção de favorecimento da cidadania e da participação social e política do indivíduo; Diretrizes Curriculares do Ensino Fundamental de 1a a 8a séries, de 2003, sustentadas por um discurso teórico-metodológico muito próximo do modelo implantado pelo documento de 2000, propondo uma prática reflexiva e compromissada para o domínio de habilidades e competências necessárias para os educandos ampliarem sua visão de mundo, no sentido de aprender, ser e conviver; Diretrizes Curriculares 10 ao 9o ano, de 2008, que buscavam a totalidade social e histórica da formação do cidadão, "[...] a compreensão de como funciona a sociedade em seus aspectos social, cultural, político e econômico, de acordo com o nível de conhecimento que esses educandos possam alcançar no seu momento de estudo" (CAMPO GRANDE, 2008a, p. 24).

A cidadania, como área de comparação, aparecia no documento de 2000 diluída nas diferentes disciplinas que compunham o currículo, com ênfase na Língua Portuguesa, delineada na perspectiva de domínio das práticas de leitura e produção de texto. Na disciplina de História, era conteúdo da Declaração Universal dos Direitos do Homem e do Cidadão. Condição semelhante foi observada no documento de 2003.

Diferentemente, o documento de 2008 trazia uma proposta de ressignificação da noção de cidadania, pautada nos princípios já traduzidos nos documentos curriculares nacionais. Essa noção era circunscrita ao exercício de direitos e deveres, como participação social e política, adotando, em seu cotidiano, atitudes de solidariedade e cooperação, rejeitando injustiça e respeitando aos outros e a si.

Tal ressignificação tomava corpo na articulação aos objetivos e à função social de algumas áreas de conhecimento, a saber: na alfabetização, "a relação entre alfabetização e cidadania pode ser analisada sob duas perspectivas, a de negação e de afirmação, sendo importante que 
se vincule o exercício da cidadania ao acesso à leitura e à escrita" (CAMPO GRANDE, 2008a, p. 205); na História, a partir das possibilidades concretas de favorecer o "estabelecimento de relações de semelhanças, diferenças cultural, social e econômica dentro de seu grupo social, proporcionando condições para que a criança conheça a si e aos outros povos e civilizações, em tempos e lugares diferentes da sociedade" (CAMPO GRANDE, 2008a, p. 210).

Sob a noção de cidadania crítica, a educação devia se dar para e pela cidadania democrática, uma vez que a "escola ocupa lugar central na elaboração de uma postura ética que entende a democracia como uma luta para defender os direitos civis e melhorar a qualidade da vida humana" (CAMPO GRANDE, 2008a, p. 5), embora admitisse que isso não fosse algo restrito à educação escolar.

A "noção de diferença" permeava o corpus de conhecimentos a ser oferecido na disciplina de Língua Portuguesa, ressaltando a importância de que os alunos

[...] compreendam e saibam respeitar as características étnicas, bem como analisar criticamente as desigualdades socioeconômicas e culturais dos diferentes grupos existentes no mundo, a começar por sua sala de aula. [...]. (CAMPO GRANDE, 2008b, v. II, p. 100);

[...] na de História, ao destacar a condição multicultural do Brasil e a necessidade de uma articulação entre a História como ciência social e os outros componentes curriculares, visando contribuir para a construção do conhecimento e o espírito de justiça, criticidade, solidariedade e o respeito à diversidade da brasileira, aos indivíduos, opções políticas, diferentes etnias (sistematizando a Lei 11.465/2008), orientações sexuais, formações religiosas, e outras condições sociais, permitindo que o articule elementos para posicionar-se diante de situações opressivas na sociedade. (CAMPO GRANDE, 2008c, v. III, p. 80).

A necessidade de conferir a determinados grupos uma proteção especial e particularizada, em face de sua própria vulnerabilidade, viria a promover o reverso das discussões do direito à sua educação. Essa prerrogativa encontrava eco apenas na desconsideração dos direitos de todos, o que exigia uma resposta diferenciada indistinta.

Nesse sentido, acabava destacando as diferenças numa perspectiva de neutralizá-las, isto é, no reconhecimento de que a educação se dirigia a indivíduos particularizados, situados no espaço e no tempo, e cujas capacidades, disposições e expectativas refletiam as características objetivas do mundo social e do mundo mental, no qual eram levados a viver.

A "noção de cultura" era tida como bem a ser usufruído (2000), vivências cotidianas (2003) e, por último (2008), como matriz impulsionadora da integração horizontal e vertical do currículo do ensino fundamental, em uma relação intrínseca entre sociedade e educação. Essa integração tomava forma na proposta de Itinerários Científicos e Culturais, concebidos como

uma atividade escolar que envolve a ciência e a cultura [...] vinculados a cultura singular/ universal, mas integrados e articulados ao processo de resgate histórico e valorização da cultura que lhes é pertinente, como conhecimentos civilizatórios da natureza humana. (CAMPO GRANDE, 2008a, p. 28-31).

"Ao observar a história, depara-se com a cultura nas suas mais variadas formas e expressas pelos grupos das classes sociais antagônicas do sistema capitalista" (CAMPO GRANDE, 2008a, p. 142). Talvez fosse essa ideia responsável pelas inúmeras adjetivações que foram ofertadas à noção de cultura ao longo desse documento, a saber: cultura do negro e do índio, cultura do campo, cultura das crianças e dos jovens, cultura corporal, cultura lúdica, cultura letrada, cultura imagética, cultura estética, entre outras. 
Esse mosaico de adjetivações interagia com conceitos de cultura produzidos nos campos da Psicologia, da História e das Artes, permitindo diferentes projeções ao conceito, mas sempre a partir da ideia de marcar uma identidade coletiva, inscrita numa relação social com "o outro", resultante de miscigenações e transformações variadas.

Sob essa perspectiva, pareceu se constituir como uma representação simbólica do mundo, ao mesmo tempo que singularizada à condição de prática interpretativa desse mesmo mundo. Isso a conduzia como sinônimo de recurso capitalizável e transmissível, potenciada por meio de uma abordagem de caráter pletórico.

Também era preciso definir a escola como lugar de cultura, ou ainda do cruzamento das culturas (PÉREZ GÓMEZ, 2001). Esse conceito não poderia ser entendido sem a identificação das estreitas relações que mantém com a política, a economia e a sociedade na qual era gerado e com a qual interagia.

\section{NOTAS FINAIS}

Os Temas Transversais foram tomados na política curricular, desencadeada em finais dos anos 1990, como mecanismos integradores, instrumentos na/da/para superação da fragmentação do conhecimento escolar, uma vez que, na sociedade contemporânea globalizada, esse conhecimento deveria ter nova configuração, passando a articular/combinar diferentes campos do saber.

Nessa proposição, compunha o chamado segundo grupo do/no processo de distribuição de conhecimentos, em que estavam localizados os conteúdos organizados em torno de temas como ética, educação ambiental, orientação sexual, pluralidade cultural e saúde.

Essas temáticas diziam respeito aos conteúdos de caráter social, incluídos no currículo do ensino fundamental de forma "transversal", não como uma área de conhecimento específica, mas como temas a serem tratados nas várias áreas que compunham o currículo, a saber: Língua Portuguesa, História, Geografia, Matemática, Ciências Naturais, Arte, Educação Física e Língua Estrangeira. Eram abordadas como "questões urgentes que devem necessariamente ser tratadas, como a violência, a saúde, o uso de recursos naturais, os preconceitos que não têm sido contempladas por essas áreas" (BRASIL, 1997, p. 23).

Objetivamente, a proposta dos temas transversais operava críticas ao chamado currículo disciplinar, sob a perspectiva de que ele não garantia a organicidade necessária ao processo de distribuição de conhecimentos que acontecia nas escolas.

No tocante à análise que propusemos, essa crítica ganhava outra perspectiva, uma vez que estávamos, também, orientados pelo tratamento das noções apontadas como questões que perpassavam a consolidação de políticas de igualdade no contexto da escolarização, ressaltando a defesa ampla dos direitos delineados na Constituição Federal vigente.

Como temas transversais, entendíamos que as noções de "Cultura, Cidadania e Diferença" seriam potencialmente propositivas nos esforços de reflexão acerca da Ética, da Orientação Sexual, do Meio Ambiente, da Saúde, da Pluralidade Cultural e do Trabalho e Consumo, particularmente pelo caráter de discursividade que evidenciavam, ao mesmo tempo que, em si, comportavam o nível de interdisciplinaridade requerido, já que transitavam nos campos da ciência jurídica e social.

Contudo pareceu não ser esse o quadro encontrado nos documentos curriculares analisados, uma vez que, ao se tornarem "conteúdos disciplinares", estavam desligados da perspectiva do investimento na vinculação com a realidade social na qual estavam imersos. Tratadas como 
conteúdos, as noções deixaram de ser temas constitutivos do debate curricular, imersas na construção do sujeito social, na articulação saber, conhecimento e vivências, mantendo-se alinhadas ao exercício do controle dos discursos e das formas de gestão dos conhecimentos, focadas no binômio ensino-aprendizagem e avaliação.

\section{REFERÊNCIAS}

BRASIL. Constituição da República Federativa do Brasil. 1988. Disponível em: <http://www.planalto.gov. br/ccivil_03/constituicao/constituicao.htm>. Acesso em: 14 set. 2016.

BRASIL. Parâmetros curriculares nacionais: introdução aos parâmetros curriculares nacionais. 1997. Disponível em: <http://portal.mec.gov.br/seb/arquivos/pdf/livro01.pdf>. Acesso em: 14 set. 2016.

CAMPO GRANDE, Cidade [de]. Secretaria Municipal de Educação. Seqüência Didática. Campo Grande: Prefeitura Municipal, 2000.

Diretrizes Curriculares do Ensino Fundamental. Campo Grande: Prefeitura Municipal, 2003.

Referencial Curricular da Rede Municipal de Ensino do 1ㅇ e 2o ano do Ensino Fundamental. Campo

Grande: Prefeitura Municipal, 2008a.

Referencial Curricular da Rede Municipal de Ensino do 3 ao 9o ano. Campo Grande: Prefeitura Municipal, 2008b. v. II.

Referencial Curricular da Rede Municipal de Ensino do 3o ao 9o ano. Campo Grande: Prefeitura Municipal, 2008c. v. III.

CAMPOS, J. C. D. Reforma agrária e educação no campo: da redistribuição da propriedade da terra à cidadania do trabalhador rural. In: ENCONTRO NACIONAL DO CONPEDI, 18., 2-4 jul. 2009, Maringá. Anais... Florianópolis: Fundação Boiteux, 2009. p. 558-70. v. 1.

RICHTER, Daniela; TERRA, R. B. M. R. B.; CASSOL, S. V. O uso da democracia participativa como meio de fortalecimento da cidadania frente à crise do estado. In: ENCONTRO PREPARATÓRIO PARA O CONGRESSO NACIONAL DO CONPEDI, 16., 13, 14 e 17 jun. 2007, Campos dos Goytacazes. Anais... Florianópolis: Fundação Boiteux: 2007.

CUCHE, Denys. A noção de cultura nas ciências sociais. Tradução de Viviane Ribeiro. Bauru: EDUSC, 1999.

FARAH, Elias. Cidadania. São Paulo: Juarez de Oliveira, 2001.

GUERRA, S. Direitos humanos e cidadania. São Paulo: Atlas, 2012.

GUIMARÃES, A. S. A. Desigualdade e diversidade: os sentidos contrários da ação. In: BOTELHO, A.; SCHWARCZ, L. M. (Org.). Cidadania, um processo em construção: minorias, justiça e direitos. São Paulo: Claro Enigma, 2012. p. 38-47.

MÉSZÁROS, I. A educação para além do capital. São Paulo: Boitempo, 2005.

MORGAN, L. S. A noção contemporânea de cidadania como pré-compreensão para a materialização dos valores ético-jurídicos fundamentais. In: ENCONTRO PREPARATÓRIO PARA O CONGRESSO NACIONAL DO CONPEDI, 16.,13, 14 e 17 jun. 2007, Campos dos Goytacazes. Anais... Florianópolis: Fundação Boiteux: 2007.

MORIN, E. Os sete saberes necessários a uma educação do futuro. São Paulo: Cortez, 2000.

PACHECO, J. A. A educação para a cidadania: o espaço curricularmente adiado. Revista Teias, Rio de Janeiro, v. 1, n. 2, p. 1-10, 2000.

PÉREZ GÓMEZ, A. A cultura escolar na sociedade neoliberal. Porto Alegre: Artmed, 2001.

RAWLS, John. Uma teoria da justiça. Tradução de Vamireh Chacon. Brasília: Editora UnB, 1981.

INTERAÇÕES, Campo Grande, MS, v. 18, n. 4, p. 197-206, out./dez. 2017. 
SILVA, J. A da. Ordenação constitucional da cultura. São Paulo: Malheiros, 2001.

VIOLA, S. E. A. Direitos Humanos no Brasil: abrindo portas sob neblina. In: SILVEIRA, R. M. G. et al. (Org.). Educação em direitos humanos: fundamentos teórico-metodológicos. João Pessoa: UFPB, 2007. v. 1.

WARREN, K. B. Os movimentos indígenas como um desafio ao paradigma do movimento social unificado na Guatemala. In: ALVAREZ, S. E.; DAGNINO, E.; ESCOBAR, A. (Org.). Cultura e política nos movimentos sociais latino-americanos: novas leituras. Belo Horizonte: Ed. UFMG, 2000.

\section{Sobre as autoras:}

Maurinice Evaristo Wenceslau: Doutora em Direito das Relações Sociais pela Pontifícia Universidade Católica de São Paulo. Professora-pesquisadora Programa de Pós-Graduação em Direitos Humanos (PPGDH) da Universidade Federal de Mato Grosso do Sul (UFMS). Líder do Grupo de Estudos e Pesquisa "Laboratório de Estudos e Pesquisa em Direitos Difusos" (LEDD). E-mail: maurinice@uol.com.br

Fabiany de Cássia Tavares Silva: Pós-doutora em Educação pela Universidade Federal de São Paulo, com estágios nas Universidades de Granada (Espanha) e Coimbra (Portugal), bolsista CNPQ PDS. Doutora em Educação pelo Programa de Estudos Pós-graduados em Educação: História, Política, Sociedade, pela Pontifícia Universidade Católica de São Paulo. Professora-pesquisadora Programa de Pós-Graduação em Educação (PPGEdu) da Universidade Federal de Mato Grosso do Sul (UFMS). Líder do Grupo de Estudos e Pesquisa "Observatório de Cultura Escolar" (OCE). Bolsista Produtividade CNPQ. E-mail: fabiany@uol.com.br 